\title{
Planting Material of Enset (Ensete ventricosum), a Key Food Security Crop in Southwest Ethiopia, Is a Key Element in the Dissemination of Plant-Parasitic Nematode Infection
}

\author{
Selamawit A. Kidane ${ }^{1,2}$, Solveig Haukeland ${ }^{3,4}$, Beira H. Meressa ${ }^{5}$, \\ Anne Kathrine Hvoslef-Eide ${ }^{1 *}$ and Danny L. Coyne ${ }^{2,6}$ \\ ${ }^{1}$ Norwegian University of Life Sciences, Ås, Norway, ${ }^{2}$ International Institute of Tropical Agriculture, PMB, Ibadan, Nigeria, \\ ${ }^{3}$ The Norwegian Institute of Bioeconomy Research, Ås, Norway, ${ }^{4}$ International Centre of Insect Physiology and Ecology, \\ Nairobi, Kenya, ${ }^{5}$ Jimma University College of Agriculture and Veterinary Medicine, Jimma, Ethiopia, ${ }^{6}$ Nematology Research \\ Unit, Department of Biology, Ghent University, Campus Ledeganck, Ledeganckstraat, Ghent, Belgium
}

OPEN ACCESS

Edited by:

Rita Hogan Mumm,

University of llinois at

Urbana-Champaign, United States

Reviewed by:

Hirut Betaw,

International Potato Centre, Ethiopia

Robooni Tumuhimbise,

National Agricultural Research

Organisation, Uganda

${ }^{*}$ Correspondence: Anne Kathrine Hvoslef-Eide trine.hvoslef-eide@nmbu.no

Specialty section: This article was submitted to

Crop and Product Physiology, a section of the journal Frontiers in Plant Science

Received: 04 February 2021 Accepted: 04 June 2021

Published: 09 July 2021

Citation:

Kidane SA, Haukeland S, Meressa BH, Hvoslef-Eide AK and Coyne DL (2021) Planting Material of Enset (Ensete ventricosum), a Key Food Security Crop in Southwest Ethiopia, Is a Key Element in the Dissemination of Plant-Parasitic Nematode Infection.

Front. Plant Sci. 12:664155. doi: 10.3389/fpls.2021.664155
Enset (Ensete ventricosum), is a perennial herbaceous plant belonging to the family Musaceae, along with banana and plantain. Despite wild populations occurring in eastern, central and southern Africa, it is only in Ethiopia that the crop has been domesticated, where it is culturally and agriculturally symbolic as a food security crop. Although an under-researched orphan crop, enset serves as a staple food for about $20 \%$ of the Ethiopian population, comprising more than 20 million people, demonstrating its value in the country. Similar to banana and plantain, enset is heavily affected by plant-parasitic nematodes, with recent studies indicating record levels of infection by the root lesion nematode Pratylenchus goodeyi. Enset is propagated vegetatively using suckers that are purposely initiated from the mother corm. However, while banana and plantain suckers have proven to be a key source of nematode infection and spread, knowledge on the infection levels and role of enset suckers in nematode dissemination is lacking. Given the high levels of plant-parasitic nematodes reported in previous surveys, it is therefore speculated that planting material may act as a key source of nematode dissemination. To address this lack of information, we assessed enset planting material in four key enset growing zones in Ethiopia. A total of 340 enset sucker samples were collected from farmers and markets and analyzed for the presence of nematodes. Nematodes were extracted using a modified Baermann method over a period of $48 \mathrm{~h}$. The root lesion nematode $P$. goodeyi was present in $100 \%$ of the samples, at various levels of infection. These conclusive results show that planting material is indeed a key source of nematode infection in enset, hence measures taken to ensure clean suckers for planting will certainly mitigate nematode infection and spread. The effect of nematode infection on yield and quality on enset remains to be investigated and would be a way forward to complement the nematode/disease studies conducted so far and add valuable knowledge to the current poorly known impact of pests and diseases.

Keywords: lesion nematode, Pratylenchus goodeyi, orphan crop, planting material quality, enset crop 


\section{INTRODUCTION}

Described as the "tree against hunger" (Costa and Lockhart, 1984), enset (Ensete ventricosum) is a perennial monocarpic single-stemmed herbaceous plant belonging to the family Musaceae, along with banana and plantain. Although wild species occur in eastern, central and southern Africa (Baker and Simmonds, 1953) enset is cultivated in, and solely unique to, Ethiopia, where it is culturally and agriculturally symbolic; cropping systems in the south and southwest are based around this pivotal, yet under-researched orphan crop. Unlike bananas, enset does not produce edible fruits, instead, it is grown for its carbohydrate-rich food obtained from the pseudostem, leaf sheaths and underground corm, which are harvested and processed into food products. Harvest can be at any time during the year, at any growth stage and the fermented products can be stored for long periods, a combination of characters that make it an important food security crop, upon which millions depend. Its value was prominently highlighted during the harsh Ethiopian famine in the 1980's when enset growing communities were unaffected by the calamity (Dessalegn, 1995). However, on a regular basis, approximately $20 \%$ of the Ethiopian population depends on enset as a key staple food crop, primarily in the south and southwestern part of the country (Borrell et al., 2019, 2020). Furthermore, it is used for several other purposes, such as animal feed, fibre, construction material and in traditional medicine. The crop best grows at cooler, higher altitudes and is found mostly between $1200-3100 \mathrm{~m}$ above sea level (Brandt et al., 1997).

Harvest commonly occurs after 4 to 6 years after transplanting, but there is variability in when plants are harvested, with indications as early as three years and up to twelve years (Brandt et al., 1997; Borrell et al., 2020). Enset is vegetatively propagated using suckers that are produced through a succession of growth stages. Unlike banana, it does not produce suckers aside the mother plant, instead suckers are purposely initiated from a mother corm, obtained from harvested plants, after cutting off the pseudostem and roots and removing the apical dominance. Corms are then buried in the ground, just below the surface, and from which multiple suckers sprout and develop. Depending on the genotype and the size of the corm, between 20-100 suckers will arise (Brandt et al., 1997). After approximately one year, these suckers are transplanted into a well-manured nursery and repeatedly replanted, up to four times, into increasingly wider spaced nurseries until the suckers are removed for use as planting material. Suckers aged two to four years are used for planting into the field, many of which are sold at designated local seedling markets each year between December and February (Olango et al., 2014). Farmers also raise their own suckers or exchange planting materials between themselves.

Similar to banana and plantain, enset is heavily affected by plant-parasitic nematodes (Coyne and Kidane, 2018). Several plant-parasitic nematodes are associated with enset, with the lesion nematode, $P$. goodeyi, considered the most important threat to the crop (Peregrine and Bridge, 1992; Bogale et al.,
2004; Addis et al., 2006; Kidane et al., 2020). For banana and plantain, the use of infected planting material (suckers) represents a key source of nematode dissemination and the perpetuation of the problem. Farmers exchange planting materials, and this practice is responsible for the continuous distribution of nematodes to new fields. The use of healthy planting materials, therefore, is essential to arrest the spread of nematodes and prevent losses due to the pests. A range of techniques is used in order to create healthy planting materials, such as through the use of in vitro tissue cultured material, macro propagation and sucker sanitation by paring and hot water treatment (Tenkouano et al., 2006; Coyne et al., 2010). The use of clean and healthy banana and plantain planting material plays a crucial role in averting the spread of nematodes and other root-borne pests and diseases and the damage they cause, especially in smallholder farming systems, where expensive management strategies are not feasible (Coyne et al., 2006).

Given the sparse knowledge by farmers of nematodes, as well as the current high incidence and levels of $P$. goodeyi infection on enset (Kidane et al., 2020), it is speculated that, similar to banana and plantain, nematodes are being disseminated to newly planted farms through the use of infected enset suckers. To date, there appears to be no information available or studies conducted to assess the level of nematode infection of enset suckers. The current study was undertaken to assess the infection status of enset planting materials as a basis for developing suitable nematode management options.

\section{MATERIALS AND METHODS}

Enset suckers aged between 1-2 years were collected from farmers (Figures 1A,B) and markets (Figure 2) in SeptemberOctober 2019 in four key enset growing zones in Ethiopia (Dawro, Keffa, Guraghe and Wolayita) (Figure 3). In each of these growing zones, 13 locations were randomly selected and 16-40 enset suckers were collected at each site. The altitude was recorded for each site. The suckers were transported to the Plant Disease Diagnostics Lab of Jimma University, where roots were carefully washed, cut longitudinally, and chopped roughly into $\sim 0.5 \mathrm{~mm}$-size pieces and a $10 \mathrm{~g}$ sub-sample used for nematode extraction. Nematodes were extracted using a modified Baermann method over a period of $48 \mathrm{~h}$ (Coyne et al., 2018). Nematode suspensions were decanted, collected on a $38 \mu \mathrm{m}$ sieve, rinsed into beakers, reduced to $10 \mathrm{ml}$ and densities counted from $1 \mathrm{ml}$ aliquots using a counting slide under a compound microscope. Nematode densities were calculated for each root sample and expressed as the number of nematodes per $10 \mathrm{~g}$ root. Pratylenchus specimens were identified to species level based on available keys (Sher and Allen, 1953; Castillo and Vovlas, 2007).

Nematode root density data were analyzed for any differences in infection levels between the regional zones. Each root sample was considered for analysis. All data were analyzed using $\mathrm{R}$ and RStudio ${ }^{\circledR}$ after $\log (\mathrm{n}+1)$ 

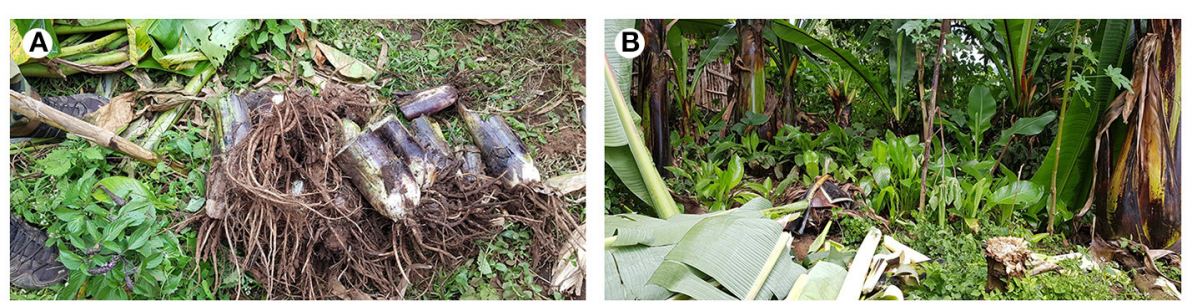

FIGURE 1 | Enset suckers (A) (B) collected from farmers' nurseries in Ethiopia.

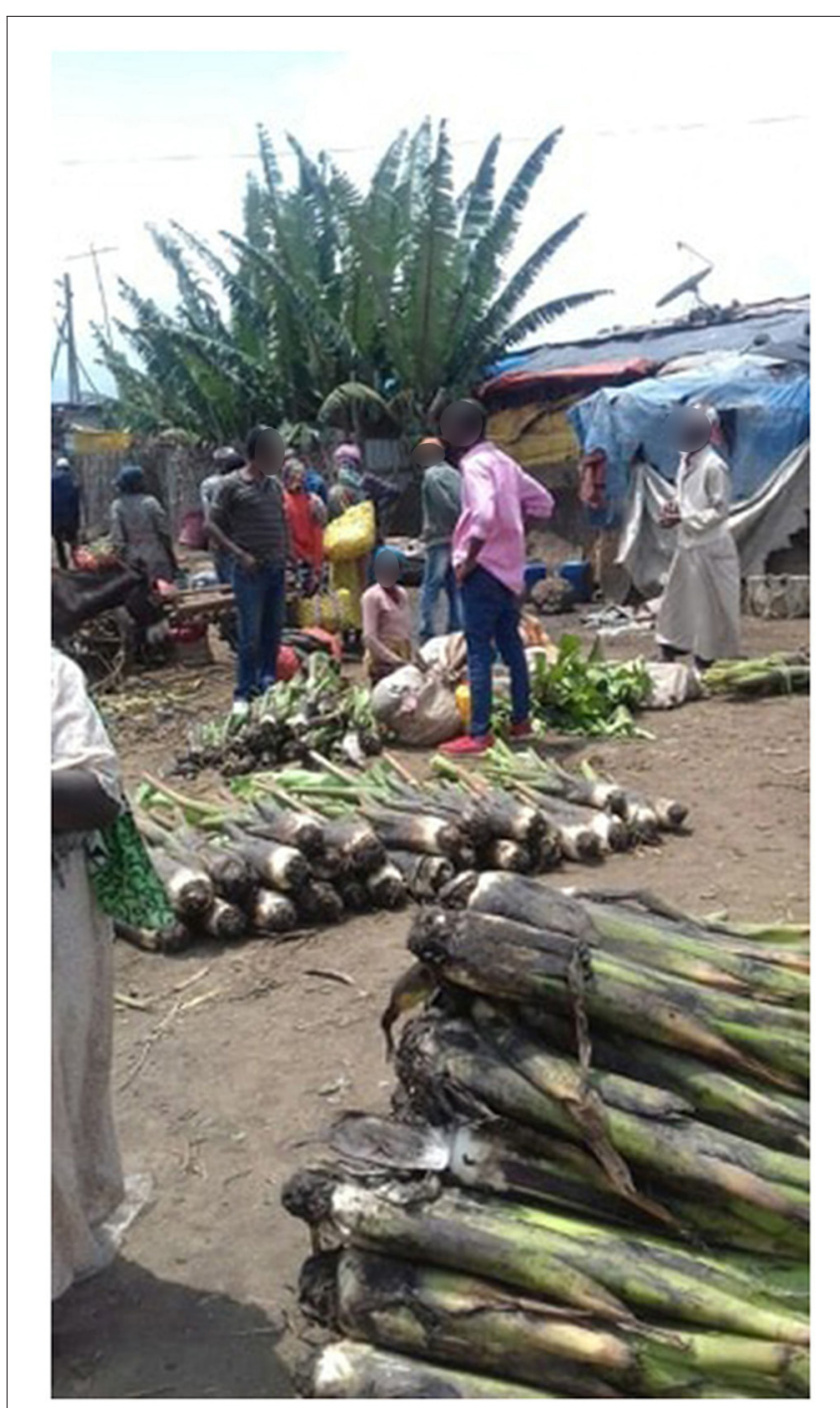

FIGURE 2 | Enset suckers collected from markets in Ethiopia.

transformation so that the data conformed to normal distribution (Zuur et al., 2010). The association between nematode density and altitude was analyzed using Pearson's correlation analysis.

\section{RESULTS}

A total of 340 enset samples each comprised of 2 to 3 suckers was assessed during the study. $P$. goodeyi was recovered from the roots of $100 \%$ of sucker samples which ranged in density from 10 and 190 per $10 \mathrm{~g}$ roots (Table 1). Apart from a few nonparasitic nematodes in some samples, $P$. goodeyi was the only plant-parasitic nematode recovered from roots. Although the age of the suckers was not specifically recorded for each sample, in general younger suckers appeared less infected, than larger, older suckers (Kidane pers. obs.). On some suckers, especially the larger, older ones, lesions were clearly evident on their roots and corms (Figure 4).

ANOVA revealed a significant difference $(P<0.05)$ in $P$. goodeyi root infection levels of sucker samples amongst sites. However, there was no correlation $(r=0.014 ; P=0.85)$ in nematode infection with altitude, across all locations.

\section{DISCUSSION}

Infection of enset planting material with $P$. goodeyi is clearly widespread across the main enset growing zones in Ethiopia, and consequently acting as a key source of contamination of new fields. The nematode-infected suckers, often visibly affected with lesions on their roots and corms, are planted into new fields. Other than trimming the roots and parts of the corms, which is a common procedure performed during transplanting, there is no further treatment undertaken to reduce the nematode infection. With $100 \%$ infection incidence of planting material during the study, it is highly likely that this reflects the situation across all enset production systems in Ethiopia. Sucker infection levels were relatively high in some cases, and infection levels varied significantly amongst samples. This variability could be attributed to differences in susceptibility of the cultivars (Kidane et al., 2021), due to high genetic diversity among cultivated landraces (Kidane et al., 2020), each with varying levels of resistance against $P$. goodeyi. The current study aimed to assess the planting material most commonly available and used by farmers, which was suckers aged 12 years. However, when processing the suckers for nematode extraction, the older, larger suckers appeared to be relatively more infected, with more apparent lesions and damage observed in general (Figure 4). The variability in sucker age across samples 
may have additionally contributed to the high variability of nematode densities.

Interestingly, just one nematode pest species was recovered during the study. While several species of plant-parasitic nematodes are associated with enset in Ethiopia, $P$. goodeyi is the principal and most prevalent species (Bogale et al., 2004; Addis et al., 2006; Kidane et al., 2020). This is unlike other members of Musaceae, such as banana and plantain, for which several species often occur in combination (Coyne and Kidane, 2018; Sikora et al., 2018). As it appears that nematode pests are being constantly disseminated through contaminated planting material that is exchanged between farmers, the implementation of interventions that can avert this should be sought. Given the similarities with banana and plantain, experiences drawn from successful sucker sanitation practices in these crops, such as paring of corms and sucker immersion in boiling water for a

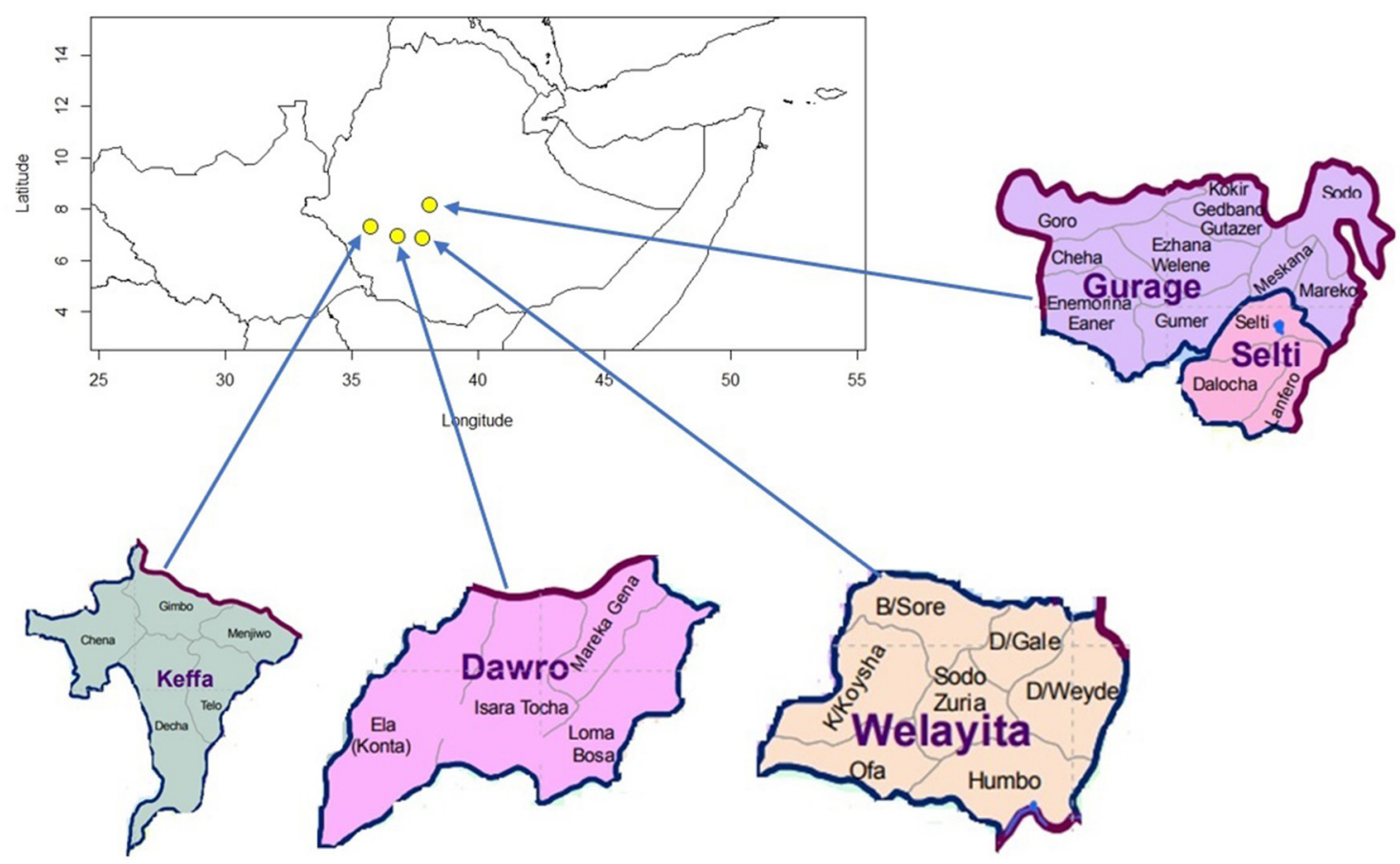

FIGURE 3 | Enset growing zones in southern Ethiopia along with sites where enset suckers were collected.

TABLE 1 | Pratylenchus goodeyi root density on enset sucker planting material collected from key enset production zones in Southern Ethiopia.

\begin{tabular}{|c|c|c|c|}
\hline Zone & Site/ elevation (m.a.s.I.) & Number of samples & Pratylenchus goodeyi mean density per $10 \mathrm{~g}$ root \\
\hline \multirow[t]{4}{*}{ Dawro } & Tercha (1400) & 24 & 141 \\
\hline & Maraka (2100-2200) & 24 & 137 \\
\hline & Marimansa (1800-2000) & 24 & 120 \\
\hline & & Total $=72$ & \\
\hline \multirow[t]{4}{*}{ Keffa } & Gimbo (1600-1900) & 24 & 93 \\
\hline & Decha (1700-2100) & 24 & 190 \\
\hline & Shishenda (1700-2200) & 24 & 174 \\
\hline & & Total $=72$ & \\
\hline \multirow[t]{5}{*}{ Guraghe } & Ezha (> 2400) & 25 & 140 \\
\hline & Meskan (2200) & 22 & 70 \\
\hline & Abeshge (1600-1700) & 16 & 69 \\
\hline & Silte (2000) & 30 & 124 \\
\hline & & Total $=93$ & \\
\hline \multirow[t]{4}{*}{ Wolayita } & Boloso soro (1700-1800) & 40 & 141 \\
\hline & Damot gale (2000) & 40 & 10 \\
\hline & Sodo zuria (2000) & 23 & 295 \\
\hline & & Total $=103$ & \\
\hline
\end{tabular}




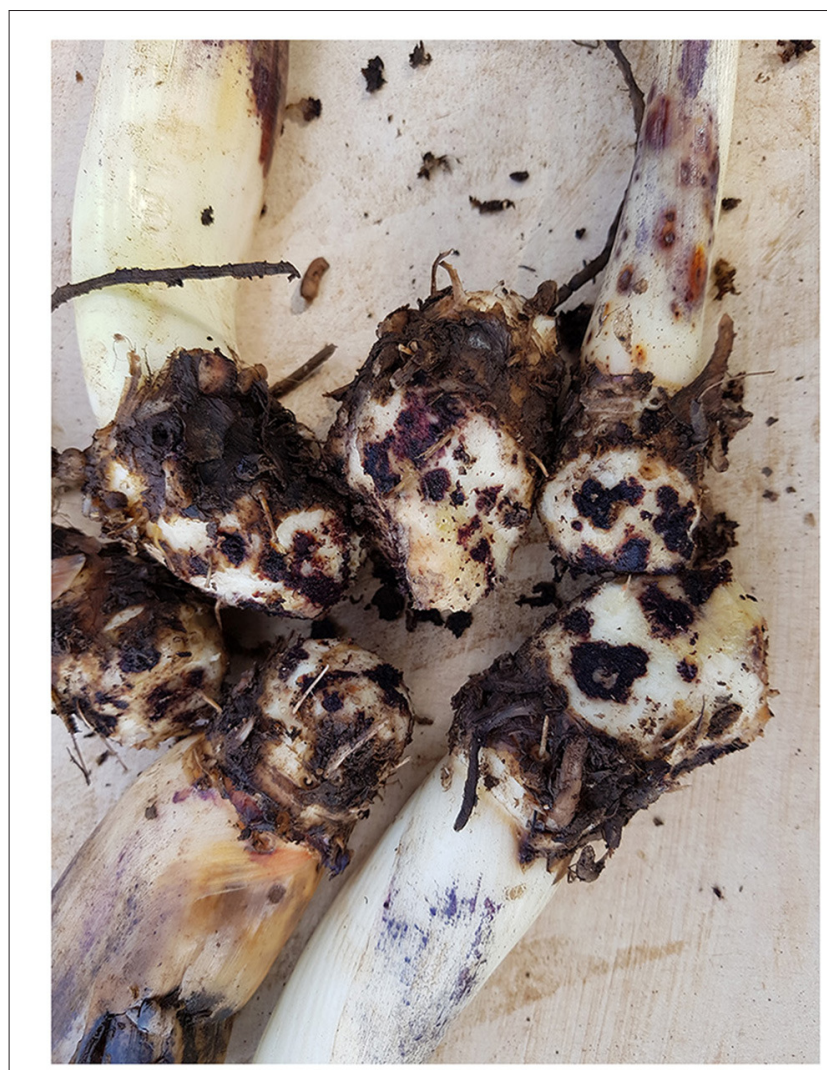

FIGURE 4 | Extensive lesioning on enset suckers collected from markets and farms in Ethiopia.

brief 30 s prior to planting (Tenkouano et al., 2006), hold promise for enset.

In the current study, we observed that enset farmers had no perception of nematodes and the possible damage that they cause. This is despite a common practice of trimming necrotic sections from suckers before transplanting. Although the suckers are trimmed and cleaned to some degree, large amounts of necrotic tissue often remained on the transplanted suckers (Figure 3), indicating a lack of awareness of the importance of this damage by farmers. To date, there is no information available on the levels or extent of the damage being caused to enset production by $P$. goodeyi. It is effectively present in all plantations, to varying degrees of infection, but can be present at extremely high densities (Kidane et al., 2020). This blanket contamination of enset crops in Ethiopia has undoubted consequences to production and quality, which requires attention. Interventions to improve awareness of nematodes, the damage they cause,

\section{REFERENCES}

Addis, T., Blomme, G., Turyagyenda, L., Van den Berg, E., and De Waele, D. (2006). Nematodes associated with enset and banana in the highlands of Ethiopia. Int. J. Nematol. 16, 118-125. and suitable management strategies are required. However, the implementation of simple and effective options for the establishment of healthy seedling systems and sucker sanitation need to be prioritized. It is not surprising that a principal mode of nematode transmission on enset is through the dissemination of contaminated planting material. The current study confirms this and provides a basis for developing management options to amend this. Despite it being an important crop in various regards, the highly localized enset-based farming system has received only limited research attention, which needs to be rectified to ensure and improve the productivity of this neglected orphan crop (Brandt et al., 1997; Borrell et al., 2020).

\section{DATA AVAILABILITY STATEMENT}

The raw data supporting the conclusions of this article will be made available by the authors, without undue reservation.

\section{AUTHOR CONTRIBUTIONS}

SK planned, performed, analyzed and wrote the manuscript, $\mathrm{SH}$ helped planning the work and contributed to the writing, $\mathrm{BM}$ contributed to the planning, $\mathrm{AH}-\mathrm{E}$ was the Project leader, contributed to the planning and contributed to the writing, DC planned, helped with the analysis and contributed to the writing of the manuscript. All authors contributed to the article and approved the submitted version.

\section{FUNDING}

The Norwegian Agency for Development Cooperation (NORAD) has funded this study, which was part of the project Controlling Disease in Sweet potato and Enset in South Sudan and Ethiopia to Improve Productivity and Livelihoods under Changing Climatic Conditions using Modern Technologies under the NORHED program (Agreement no. ETH-13/0017).

\section{ACKNOWLEDGMENTS}

The authors thank Norwegian Agency for Development Cooperation (NORAD) for funding this study, which is part of the project Controlling Disease in Sweet potato and Enset in South Sudan and Ethiopia to Improve Productivity and Livelihoods under Changing Climatic Conditions using Modern Technologies under the NORHED program (Agreement no. ETH-13/0017) and also the European Union project: Microbial Uptakes for Sustainable management of major banana pests and diseases, Grant Agreement 727624. 
Borrell, J. S., Biswas, M. K., Goodwin, M., Blomme, G., Schwarzacher, T., HeslopHarrison, J. S., et al. (2019). Enset in Ethiopia: a poorly characterized but resilient starch staple. Ann. Bot. 123, 747-766. doi: 10.1093/aob/mcy214

Borrell, J. S., Goodwin, M., Blomme, G., Jacobsen, K., Wendawek, A. M., Gashu, D., et al. (2020). Enset-based agricultural systems in Ethiopia: a systematic review of production trends, agronomy, processing and the wider food security applications of a neglected banana relative. Plants People Planet 2, 212-228. doi: $10.1002 /$ ppp3.10084

Brandt, S., Spring, A., Hiebsch, C., McCabe, J., Tabogie, E., Diro, M., et al. (1997). The "Tree Against Hunger": Enset-Based Agricultural Systems in Ethiopia. Washington, DC: American Association for the Advancement of Science.

Castillo, P., and Vovlas, N. (2007). Pratylenchus (Nematoda: Pratylenchidae): Diagnosis, Biology, Pathogenicity and Management. Leiden: Brill. doi: 10.1163/ej.9789004155640.i-523

Costa, M. G. D. A., and Lockhart, D. M. (1984). The Itinerario of Jeronimo Lobo. London: Hakluyt Society.

Coyne, D., Kajumba, C., and Kagoda, F. (2006). "Improved banana performance in East Africa through nematode management interventions at the International Institute of Tropical Agriculture," in INIBAP Proceedings. 'Farmer-Participatory Testing of Banana IPM Options for Sustainable Banana Production in Eastern Africa', 8-9 December, 2003. 141-148

Coyne, D., and Kidane, S. (2018). "Nematode pathogens," in Handbook of Diseases of Banana, Abaca And Enset, ed D. R. Jones (Wallingford, UK: CAB International), 429-461. doi: 10.1079/9781780647197.0429

Coyne, D., Wasukira, A., Dusabe, J., Rotifa, I., and Dubois, T. (2010). Boiling water treatment: a simple, rapid and effective technique for nematode and banana weevil management in banana and plantain (Musa spp.) planting material. Crop Protect. 29, 1478-1482. doi: 10.1016/j.cropro.2010.08.008

Coyne, D. L., Nicol, J. M., and Claudius-Cole, A. (2018). Practical Plant Nematology: A Field and Laboratory Guide, 3rd Edn. Ibadan, Nigeria: International Institute of Tropical Agriculture (IITA). 82.

Dessalegn, R. (1995). Resilience and vulnerability: enset agriculture in southern Ethiopia. J. Ethiop. Stud. 28, 23-51.

Kidane, S. A., Meressa, B. H., Haukeland, S., Hvoslef-Eide, A. K., and Coyne, D. L. (2021). The Ethiopian staple food crop enset (Ensete ventricosum) assessed for the first time for resistance against the root lesion nematode Pratylenchus goodeyi. Nematology 0, 1-9. doi: 10.1163/15685411-bja10075
Kidane, S. A., Meressa, B. H., Haukeland, S., Hvoslef-Eide, A. K., Magnusson, C., Couvreur, M., et al. (2020). Occurrence of plant-parasitic nematodes on enset (Ensete ventricosum) in Ethiopia with focus on Pratylenchus goodeyi as a key species of the crop. Nematology 0 1-13. doi: 10.1163/15685411-bja 10058

Olango, T. M., Tesfaye, B., Catellani, M., and and, Pè, M. E. (2014). Indigenous knowledge, use and on-farm management of enset (Ensete ventricosum (Welw.) Cheesman) diversity in Wolaita, Southern Ethiopia. J. Ethnobiol. Ethnomed. 10:41. doi: 10.1186/1746-4269-10-41

Peregrine, W., and Bridge, J. (1992). The lesion nematode Pratylenchus goodeyi an important pest of ensete in Ethiopia. Int. J. Pest Manage. 38, 325-326. doi: 10.1080/09670879209371719

Sher, S. A., and Allen, M. W. (1953). Revision of the genus Pratylenchus (Nematoda: Tylenchidae). Univ. Calif. Publ. Zool. 57, 441-470.

Sikora, R. A., Coyne, D. L., and Quénéhervé, P. (2018). "Nematode parasites of bananas and plantains," in Plant Parasitic Nematodes in Subtropical and Tropical Agriculture, $3 r d$ Edn, eds R. A. Sikora, D. L. Coyne, J. Hallman, P. Timper (Wallingford, UK: CAB International), 617-657. doi: 10.1079/9781786391247.0617

Tenkouano, A., Hauser, S., Coyne, D., and Coulibaly, O. (2006). Clean planting materials and management practices for sustained production of banana and plantain in Africa. Chron. Horticult. 46, 14-18.

Zuur, A. F., Ieno, E. N., and Elphick, C. S. (2010). A protocol for data exploration to avoid common statistical problems. Methods Ecol. Evolut. 1, 3-14. doi: 10.1111/j.2041-210X.2009.00001.x

Conflict of Interest: The authors declare that the research was conducted in the absence of any commercial or financial relationships that could be construed as a potential conflict of interest.

Copyright (c) 2021 Kidane, Haukeland, Meressa, Hvoslef-Eide and Coyne. This is an open-access article distributed under the terms of the Creative Commons Attribution License (CC BY). The use, distribution or reproduction in other forums is permitted, provided the original author(s) and the copyright owner(s) are credited and that the original publication in this journal is cited, in accordance with accepted academic practice. No use, distribution or reproduction is permitted which does not comply with these terms. 